\title{
The effects of nitric oxide on the immune response during giardiasis
}

\author{
Authors \\ Wander Rogério \\ Pavanelli, $\mathrm{PhD}^{1}$ \\ Fredy Roberto Salazar \\ Gutierrez, $\mathrm{PhD}^{2}$ \\ Jean Jerley Nogueira da \\ Silva, $\mathrm{PhD}^{3}$ \\ Ivete Conchon Costa, \\ $\mathrm{PhD}^{1}$ \\ Maria Claudia Noronha \\ Dutra de Menezes, Msc \\ Francisco José de Abreu \\ Oliveira, $\mathrm{Msc}^{1}$ \\ Eiko Nakagawa Itano, \\ $\mathrm{PhD}^{1}$ \\ Maria Angélica Ehara \\ Watanabe, $\mathrm{PhD}^{1}$ \\ ${ }^{1}$ Department of Pathology \\ Science, CCB, State \\ University of Londrina- \\ UEL, Londrina, PR. \\ ${ }^{2}$ Universidad Antonio \\ Nariño - Sede Bogotá - \\ U.A.N. \\ ${ }^{3}$ Institute of Physic of \\ São Carlos, University \\ of São Paulo, Brazil.
}

Submitted on: 06/29/2010 Approved on: 08/03/2010

\section{Correspondence to:}

Wander R Pavanelli

Universidade Estadual de

Londrina-UEL / Rodovia

Celso Garcia Cid

Campus Universitário,

Cx. Postal 6001,

86051-990, Londrina-PR

Fone: (43) 3371-4539,

Fax: (43) 3328-4440

E-mail: wanderpavanelli@

uel.br or

wanderpavanelli@usp.br

Financial Support:

Fundação Araucária-

Curitiba-Pr, Chamada

de projetos 01/2008-

Pesquisador Visitante and

Faepe-UEL.

This paper is based on a part of the Postdoctorate of Pavanelli, W.

We declare no conflict of interest.

\begin{abstract}
Nitric oxide (NO) is a free radical synthesized from L-arginine by different isoforms NO-synthases. NO possesses multiple and complex biological functions. NO is an important mediator of homeostasis, and changes in its generation or actions can contribute or not to pathological states. The knowledge of effects of NO has been not only important to our understanding of immune response, but also to new tools for research and treatment of various diseases. Knowing the importance of $\mathrm{NO}$ as inflammatory mediator in diverse infectious diseases, we decided to develop a revision that shows the participation/effect of this mediator in immune response induced against Giardia spp. Several studies already demonstrated the participation of NO with microbicidal and microbiostatic activity in giardiasis. On the other hand, some works report that Giardia spp. inhibit NO production by consuming the intermediate metabolite arginine. In fact, studies in vitro showed that G. lamblia infection of human intestinal epithelial cells had reduced NO production. This occurs due to limited offer of the crucial substrate arginine (essential aminoacid for NO production), consequently reducing NO production. Therefore, the balance between giardial arginine consumption and epithelial NO production could contribute to the variability of the duration and severity of infections by this ubiquitous parasite.
\end{abstract}

Keywords: nitric oxide; immune system; giardiasis.

[Braz J Infect Dis 2010;14(6):606-612]@Elsevier Editora Ltda.

\section{INTRODUCTION}

Nitrogen monoxide, also called nitric oxide (NO) is a radical with a small molecular weight $(30 \mathrm{kDa})$ that performs multiple biological activities. ${ }^{1,2}$ Since its discovery, an increasing number of studies have attempted to address the biochemistry of this freely diffusible second messenger and the connections with its biological properties. This molecule became the focus of intensive biological and clinical research., As a consequence, pharmaceutical industries have shown increasing interest in NO manipulation in the last years, because this free radical could be used as a potential therapeutic target in a vast variety of conditions, ranging from inflammation to degenerative diseases.

It is known that NO can directly and indirectly modulate the immune response through diverse mechanisms such as mediating microbicidal effects of NO-derived free radicals, mostly within macrophages and other phagocytes. Modulation of leukocyte effector mecha- nisms during the infection has been also observed. However, due to its regulatory effects, NO plays a dual role in the elicited response, dictated by the concentration in the inflammatory microenvironment. Of note, a deregulated NO production is observed in infected individuals, which is associated with collateral toxicity for host cells, leading to immunopathology, autoimmune responses or persistence of the parasite due to immune evasion.

\section{Nitric oxide production}

From an evolutionary point of view, NO formation may have originated as a first-line defense for metazoan cells against intracellular pathogens. This is confirmed by the wide occurrence of the enzyme responsible for $\mathrm{NO}$ production: NO-synthase (NOS) responses in several species, ranging from invertebrates such as Limulus polyphemus, ${ }^{5}$ insects, ${ }^{6,7}$ to mammals and non-mammal vertebrates. ${ }^{8-10}$ The NO signaling mechanisms would evolve only later for signaling. In mammals, the NO response is 
raised in response to infection by a wide variety of intracellular pathogen unicellular organisms such as bacteria, yeast and parasites (e.g., Leishmania spp. and T. cruzi). ${ }^{11}$ It appears that evolutionary diversity has been acquired at the level of the transcription factors involved in NO synthesis in response to different kinds of stress stimuli.

Three forms have been described: neuronal (nNOS, NOS1), endothelial (eNOS, NOS3) and inducible (iNOS, NOS2). ${ }^{12,13}$ The first two are constitutively expressed (NOS1 and NOS3), but can also be upregulated to release substantial amounts of NO mainly in the central and peripheral nervous system and vascular endothelial cells, respectively. The iNOS is induced mainly in macrophages, but can be induced in a vast variety of cells when stimulated by cytokines and polysaccharides. NO is biosynthesized by one of the NO synthases (NOS) in an oxidative reaction that mediates the incorporation of molecular oxygen $\left(\mathrm{O}_{2}\right)$ into the unstable intermediate NO-hydroxy-L-arginine (NOHA), and subsequently into L-citrulline.

This reaction consumes reducing equivalents in the form of NADPH. The final products of this reaction are NADP+, L-citrulline and NO. ${ }^{14}$

$\mathrm{L}$-arginine is the main substrate for NO synthesis. The participation of L-arginine in the inflammatory response may occur through two basic mechanisms: (I) as precursor for NO production through the activation of iNOS, mainly in macrophages; and (II) as precursor for the synthesis of metabolites required for $\mathrm{T}$ lymphocyte proliferation and effector function. ${ }^{15,16}$

The regulation of NO synthesis within cells can be exerted at various checkpoints such as: compartmental distribution of NOS, changes in NOS gene expression, enzymatic competition by Arginase. Arginase activity is a major regulatory mechanism for $\mathrm{NO}$ biosynthesis. It leads to the production of ornithine and urea. Moreover, it can modulate inflammatory response at several levels including (I) the production of ornithine, a precursor of proline, favoring cellular regeneration, wound healing and repair; ${ }^{17}$ (II) the production of polyamines, also from ornithine, which can regulate macrophage function; ${ }^{18}$ (III) regulating arginine availability and, therefore, decreasing $\mathrm{NO}$ production and other arginine mediated processes such as normal $\mathrm{T}$ lymphocyte proliferation. ${ }^{19}$ The decisive mechanism by which $\mathrm{L}$-arginine affects the balance of the cellular immune response is ultimately determined by the predominant cytokine pattern expressed in a given pathogenic process. While NO synthases are induced or up-regulated mainly during T-helper 1 inflammatory conditions, the arginase system is mainly induced in macrophages, when the predominance of T-helper 2 cytokines..$^{20}$ Moreover, uncoupling NOS from L-arginine results in the generation of NO scavenger, superoxide, and peroxynitrite, repression of the translation and stability of inducible NOS protein, inhibition of inducible NOS activity via the generation of urea, and by sensitization of NOS to its endogenous inhibitor, asymmetric dimethyl-L-arginine. ${ }^{21}$

Moreover, they are also differentially modulated according to the stimulus and the type of cytokines present in the inflammatory microenvironment. ${ }^{20}$ The products and intermediary molecules from both pathways act as modulators of the immune response.

The expression and activity of enzymes involved in NO synthesis are differentially modulated depending on different biological milieu conditions. ${ }^{13,22}$ The diverse actions of NO could be explained by its capacity to chemically attack several molecules containing metals. Moreover, soluble mediators of immune responses can differentially modulate the inducible isoform of NOS. It can be quickly enhanced in cells of the innate ${ }^{23}$ and adaptive immune response after some cytokines are produced, mainly IFNg, TNFa, IL-1b. These cytokines are produced in response to pathogen associated molecular patterns (PAMPs), which can be sensed mainly by the action of pattern recognition receptors (PRR), such as Toll-like receptors (TLRs). ${ }^{24,25}$ Signaling through these innate immune recognition receptors leads to activation of transcription factors NF- $\kappa \mathrm{B}$ and AP-1, which regulate the expression of iNOS. ${ }^{26}$

\section{Effects of nitric oxide on the immune system}

One of the most prominent functions of NO in the immune system is its participation in protective immunity against various intracellular pathogens including viruses, bacteria and protozoa. Furthermore, the killing activity of $\mathrm{NO}$ has also been showed effective in host defense against tumor cells ${ }^{27}$ and alloantigens. ${ }^{28}$ Considering its direct microbial toxicity, $\mathrm{NO}$ can exert a microbiostatic or microbicidal effect, or even act as a microbial metabolic product. ${ }^{29}$ Although these direct cellular effects of NO over pathogen biology are not yet fully understood, the strong oxidative capacity of NO and its sub-products appears to act in synergism with other lethal reactive oxidant species $\left(\mathrm{H}_{2} \mathrm{O}_{2}\right.$, etc), accounting for most of the host's microbial toxicity. Peroxynitrite (ONOO) induces modifications of selected molecular targets in a parasite and is a major mechanism for direct effects of NO, and such targets are starting to be revealed. ${ }^{30-33}$ Peroxynitrite can induce nitration of tyrosine residues as well as the reversible binding of NO to metal centers in microbial targets that are involved in vital processes, including nutrition and respiration. In various infections, cysteine-containing proteins, metalloproteins, calcium transport systems, ${ }^{34}$ as well as essential enzymes of energy metabolism ${ }^{35}$ have been identified as important intracellular targets for the toxic actions of peroxynitrite. Among them, cysteine proteinases are critical factors for virulence or replication of many pathogens (including viruses, bacteria, fungi, and parasites). ${ }^{36-38}$ 
Depending on the individual characteristics of molecules, it can lead to either the activation or inactivation of the respective protein function. Exacerbated production of $\mathrm{NO}$ and the consequent exaggerated levels of "reactive nitrogen species" (RNS) can unbalance the homeostatic mechanisms of the host, mediating collateral host toxicity and this could be the basis for certain pathologies related to nitrosative and oxidative stress. ${ }^{39-41}$ Indeed, the presence of nitrosylated tyrosine residues (Nitro tyrosine) has been recognized as an indicator of cell damage and inflammation, as well as of the production of ONOO. In addition to the direct toxicity, other effects of NO over leukocyte biology were described, which can influence several physiological processes ranging from DNA transcription ${ }^{42}$ and replication ${ }^{43}$ to protein synthesis ${ }^{44}$ and secretion. The signaling processes through which $\mathrm{NO}$ acts to regulate immune cells are extremely complex and are only just beginning to be revealed, but are largely indirect through generation of reactive nitrogen oxide species that chemically modify enzymes, signaling proteins and transcription factors. The role of NO might depend on the stage of a disease (i.e., early or late disease stages). And for a given cell, the response to NO will depend on its reactivity state and on the microenvironment as well.

\section{Nitric oxide in giardiasis}

Giardia intestinalis is the causative agent of giardiasis, a widespread intestinal infectious disease in humans. ${ }^{45}$ It is known that human infection with Giardia lamblia often results in severe abdominal cramps and malabsorptive diarrhea. While most infections are controlled by an effective immune response, some individuals develop chronic diseases that occur occasionally in the absence of apparent immunodeficiency. ${ }^{46,47}$ Have been shown that NOS1, but not NOS2, is necessary for clearance of Giardia infection. The authors also suggested that increased gastrointestinal motility contributes to the parasite elimination and this is the first example of NOS1 being involved in the elimination of an infection. ${ }^{48}$ In fact, the intestinal hypermotility is an important host mechanism of defense against Giardia. This defense appears to depend on the development of a normal adaptive immune response against the parasite, as it did not occur in mice lacking $\mathrm{T}$ and B-cells, although it is possible, in principle, that $\mathrm{T}$ or B-cells contribute to hypermotility independent of their role in adaptive antigiardial immunity. ${ }^{49}$ It is likely that similar changes in intestinal transit in humans contribute to the symptoms associated with this infection. However, it is not yet clear what immune mechanisms are responsible for effective control of infections. ${ }^{50,51}$ Therefore, further investigation into the pathophysiology of giardiasis is needed as no pathogenic mechanisms have yet been identified. Based on this consideration, the following sections focus on the importance of specific host effector mechanisms against Giardia. Elucidation of these mechanisms is not only important for understanding mucosal immune defense against this parasite, but also provides a crucial basis in the rational development of therapeutic strategies for activating the most effective host defenses against Giardia. It is believed that antimicrobial products synthesized by epithelial cells in the small intestine are good candidates. One of these is $\mathrm{NO}$, which has an antimicrobial effect (microbiostatic and microbicidal) on a wide range of microorganism ${ }^{52-66}$ and multiple functions, including increased cytotoxicity of activated macrophages. ${ }^{67}$ In polarized intestinal epithelial cells, the stable NO end products, nitrite and nitrate, are preferentially detected on the apical side, ${ }^{68}$ suggesting that Giardia could be a relevant target for epithelial cell-derived $\mathrm{NO}$ and its metabolites. The underlying mechanisms for apical NO release are not known, but might be related to the preferential localization of iNOS at the apical side of polarized epithelial cells underneath the cell membrane. ${ }^{69,70}$ Consistent with a role of epithelial cell-produced $\mathrm{NO}$ as a potential antigiardial effector molecule, $\mathrm{NO}$ was found to inhibit proliferation of $G$. lamblia trophozoites in vitro, but not to kill them. ${ }^{6}$ Thus, NO was cytostatic rather than cytotoxic for trophozoites in these studies. Another report suggested that $\mathrm{NO}$ can kill trophozoites in vitro, ${ }^{71}$ although that study used minimal media (i.e., buffered salt solution) for culture, which may have exaggerated the results, as such media do not support prolonged trophozoite viability and growth even in the absence of NO. In addition, it was observed that NO also inhibited G. lamblia excitation and encystations of in vitro. ${ }^{68}$ Growth inhibition may be important for the infected host, because local trophozoite growth is probably crucial for the ability of $G$. lamblia to establish and maintain infection of the proximal small intestine. In contrast, inhibition of encystation by NO could reduce the formation and passing of infectious cysts and, thereby, transmission to other potential hosts.

Fernandes and Assreuy ${ }^{71}$ studied the role of nitric oxide and superoxide in G. lamblia killing and verified that from the vast array of cytotoxic molecules potentially produced by defense cells, NO seems to account for the majority, if not all, of macrophage giardicidal effects. The genome from Giardia spp. has been completely sequenced, ${ }^{72}$ leading to the conclusion that Giardia is an early diverging protozoon with very simplified metabolic pathways. Although Giardia spp. have a relatively poor tolerance to $\mathrm{O} 2$, they preferentially colonize the fairly aerobic upper part of the small intestine (duodenum and jejunum). They lack the conventional respiratory oxidases, as well as the systems (catalase, superoxide dismutase, glutathione reductase) responsible for the scavenging of radical oxygen species (ROS). ${ }^{73}$

Data from Li et al. ${ }^{48}$ involving human infection with $G$. lamblia, indicate that signals mediated by enzymes nitric oxide synthases (NOS1 but not NOS2) play a key role in eliminating this infection. 
The hypothesis of contact of G. lamblia with intestinal epithelial cells might lead to release of specific proteins. ${ }^{74}$ Results have shown host-cell stimulated secretion of giardial proteins, which have the potential to be involved in the immunological events during initiation of infection and subsequent survival of the parasite in the host. In vitro studies with recombinant arginine deiminase showed that the secreted Giardia proteins could disable host innate immune factors such as nitric oxide production.

Eckmann et al. ${ }^{68}$ detected that G. lamblia and intestinal epithelial cells compete for arginine and have several implications for understanding the pathogen-host interaction [between pathogen and host]. According to Eckmann, the reduction of arginine availability could be considered a virulence mechanism of the pathogen, because it inhibited epithelial NO production, thereby subverting a potential host defense against G. lamblia. Both intestinal epithelial cells and G. lamblia trophozoites have highly efficient arginine transporter systems with comparable substrate affinities suggesting that Giardia may have an advantage over the host in taking up arginine. Thus, in models of human intestinal epithelium, G. lamblia inhibited epithelial NO production by consuming arginine, the crucial substrate used by epithelial NO synthase to form NO. These results indicate that contact of Giardia spp. with epithelial cells triggers metabolic enzyme release, which might facilitate effective colonization of the human small intestine.

It is known that the flavodiiron proteins are widespread among strict or facultative anaerobic prokaryotes, where they are involved in the response to nitrosative and/or oxidative stress. These flavodiiron proteins were fairly recently identified in a restricted group of microaerobic protozoa, including G. intestinalis. Ringqvist et al. ${ }^{74}$ proposed that in $G$. intestinalis the primary function of flavodiiron proteins is to efficiently scavenge $\mathrm{O}_{2}$, allowing this microaerobic parasite to survive in the human small intestine, thus promoting its pathogenicity.

\section{B and T-cells, antibodies, cytokines and nitric oxide in human giardiasis}

Despite the clinical symptoms, diarrhea, abdominal pain, malabsorption and weight loss, infection is not accompanied by significant mucosal inflammation. ${ }^{75}$ The infections are normally self-limiting, as immunocompetent hosts can control and typically eradicate G. lamblia, a process that involves $\mathrm{T}$ and B-cells. ${ }^{50,51,76,77}$

Several studies suggest an important role for B-cells in clearing Giardia infection. For example, infections of humans with G. lamblia result in the production of antigiardial antibodies of the IgA, IgM and IgG isotypes in mucosal secretions and serum. The specific antibody production correlates with giardial clearance..$^{50,78}$
Moreover, secretory antibodies of the IgA and IgM isotypes are attractive candidates for immune defense against Giardia spp., because they are secreted in large quantities into the intestinal lumen and their actions are antigen-specific. In this regard, parasite-specific IgA antibodies in infected children has been evaluated by several investigators. ${ }^{79,80}$ In previous studies, a $31-\mathrm{kD}$ protein and $57-\mathrm{kD}$ heat-shock protein (HSP), strong candidates for peptide vaccine, were recognized by specific IgA antibody to Giardia spp.. ${ }^{79}$ Additionally, it was shown by immunoblotting that children with chronic infections with $G$. intestinalis did not show an IgA response to the $57-\mathrm{kD}$ G. intestinalis HSP, which suggested an impairment of the switch from an IgM response to an IgG or IgA response. ${ }^{80}$

These results together showed that the clearance of human G. intestinalis infection is dependent on antibodies directed against parasite proteins and T-cell activity. However, it remains to be determined if and how cellular immune responses might contribute to control G. lamblia infections in humans.

Of the T-cells, CD4+ but not CD8+ cells are responsible for cytokine production operating in the recruitment of cells and the immunopathogenesis of the disease.$^{81}$ One of the main cytokines that appears to be associated with allergy cases in human giardiasis is the IL-6.

In fact, Mahmoud et al. ${ }^{82}$ demonstrated that there is a direct relationship between IL-6 levels increases and improved expression of adhesion molecules: the intercellular adhesion molecule-1 (ICAM-1) and vascular cell adhesion molecule-1 (VCAM-1) as mediators in development of skin allergy caused by giardiasis. Byraktar et al ${ }^{83}$ found that pro-inflammatory mediators, such as IL- 6 , and IL- $1 \beta$, and a chemokine, IL- 8 that attracts neutrophils to the site of infection, were not elevated in giardiasic children without allergy, suggesting that these cytokines may have no influence on immunity to giardiasis. However, in allergy-associated giardiasis patients, strong correlations between IL- 6 and nitric oxide were seen.

The role of transforming growth factor-betal (TGF- $\beta 1$ ) in intestinal parasitic infections has attracted significant attention, as in vitro tests showed that TGF- $\beta 1$ stimulates the isotype switch to IgA, as well as IgA secretion by LPS-stimulated B cells from Peyers patches and spleen. ${ }^{84,85}$ Knowing this peculiar property, Taherkhan et al..$^{86}$ confirm that there was a relationship between TGF- $\beta 1$ cytokines polymorphism and susceptibility to giardiasis. They found that the prevalence of allele $C$ and CC genotypes of TGF- $\beta 1 \mathrm{~T}+869 \mathrm{C}$ polymorphism was significantly higher in the patients with symptomatic giardiasis and these patients had significantly lower levels of S-IgA compared to the asymptomatic and control groups.

Based in previous report, secretory $\operatorname{IgA}$ antibodies have a central role in antigiardial defense. B-cell- 
independent mechanisms also exist and can contribute to eradication of the parasite, although their identity and physiological importance are poorly understood currently, mainly in human models. So, the elucidation of key antigiardial effector mechanisms will be important to understand mucosal immune defense against this parasite and suggest new pharmacological targets for drug therapy.

\section{CONCLUSIONS}

A delicate, not completely understood interplay do exist between the components of immune response and the levels of nitric oxide. Vast scientific evidence show that NO can exert its effects on the immune response either directly or through the activity of its derivatives (mainly oxygen and nitrogen reactive species), which are able to induce structural modifications, thus altering their biological activities. In the same way, NO is able to affect the biology of Giardia, either by direct toxicity, or through affecting essential metabolites, or even by enhancing the immune response against the parasite. Despite the potent antigiardial activity of NO, G. lamblia is not simply a passive target for host-produced NO, but has strategies to evade this potential host defense. Studies define NO and arginine as central components in a novel cross talk between a pathogen and immune response in intestinal epithelium, but the balance between giardial arginine consumption and epithelial NO production could contribute to the variability in the duration and severity of infections by this ubiquitous parasite. However, additional studies are required to further understand the multiple roles played by $\mathrm{NO}$ in giardiasis.

\section{ACKNOWLEDGEMENTS}

The authors want to thank the participation and discussions of all past and current members of the working group on immunoparasitology at UEL.

\section{REFERENCES}

1. Furchgott RF, Zawadzki JV The obligatory role of endothelial cells in the relaxation of arterial smooth muscle by acetylcholine. Nature 1980; 288:373-6.

2. Moncada S, Radomski MW, Palmer RM. Endothelium-derived relaxing factor. Identification as nitric oxide and role in the control of vascular tone and platelet function. Biochem Pharmacol 1988; 37:2495-501.

3. Moncada S, Palmer RM, Higgs EA. Nitric oxide: physiology, pathophysiology, and pharmacology. Pharmacol Rev 1991; 43:109-42.

4. Lancaster JR Jr Simulation of the diffusion and reaction of endogenously produced nitric oxide. Proc Natl Acad Sci USA 1994; 91:8137-41.

5. Nathan C, Xie QW. Regulation of biosynthesis of nitric oxide. J Biol Chem 1994; 269:13725-8.

6. Regulski M, Tully T. Molecular and biochemical characterization of dNOS: a Drosophila Ca2+/calmodulin-dependent nitric oxide synthase. Proc Natl Acad Sci U S A 1995; 92:9072-6.
7. Ribeiro JM, Hazzard JM, Nussenzveig RH et al. Reversible binding of nitric oxide by a salivary heme protein from a bloodsucking insect. Science 1993; 260:539-41.

8. Sung YJ, Hotchkiss JH, Austic RE, Dietert RR. L-argininedependent production of a reactive nitrogen intermediate by macrophages of a uricotelic species. J Leukoc Biol 1991; 50:49-56.

9. Lin AW, Chang CC, McCormick CC. Molecular cloning and expression of an avian macrophage nitric-oxide synthase cDNA and the analysis of the genomic 5-flanking region. J Biol Chem 1996; 271:11911-9.

10. Holmqvist BI, Ostholm T, Alm P, Ekstrom P. Nitric oxide synthase in the brain of a teleost. Neurosci Lett 1994; 171:205-8.

11. Liew FY, Wei XQ, Proudfoot L. Cytokines and nitric oxide as effector molecules against parasitic infections. Philos Trans R Soc Lond B Biol Sci 1997; 352:1311-5.

12. Alderton WK, Cooper CE, Knowles RG. Nitric oxide synthases: structure, function and inhibition. Biochem J 2001; 357:593-615.

13. Nathan C. Nitric oxide as a secretory product of mammalian cells. Faseb J 1992; 6:3051-64.

14. Schmidt HH, Hofmann $\mathrm{H}$, Schindler $\mathrm{U}$ et al. NO from NO synthase. Proc Natl Acad Sci USA 1996; 93:14492-7.

15. Barbul A, Sisto DA, Wasserkrug HL, Efron G. Arginine stimulates lymphocyte immune response in healthy human beings. Surgery 1981; 90:244-51.

16. Ochoa JB, Strange J, Kearney P et al. Effects of L-arginine on the proliferation of $\mathrm{T}$ lymphocyte subpopulations. JPEN J Parenter Enteral Nutr 2001; 25:23-9.

17. Morris SM, Jr, Kepka-Lenhart D, Chen LC. Differential regulation of arginases and inducible nitric oxide synthase in murine macrophage cells. Am J Physiol 1998; 275:E740-7.

18. Li H, Meininger CJ, Hawker JR, Jr, Haynes TE, Kepka-Lenhart D, Mistry SK et al. Regulatory role of arginase I and II in nitric oxide, polyamine, and proline syntheses in endothelial cells. Am J Physiol Endocrinol Metab 2001; 280:E75-82.

19. Taheri F, Ochoa JB, Faghiri Z et al. L-Arginine regulates the expression of the T-cell receptor zeta chain (CD3zeta) in Jurkat cells. Clin Cancer Res 2001; 7:958s-965s.

20. Munder M, Eichmann K, Moran JM et al. Th1/Th2-regulated expression of arginase isoforms in murine macrophages and dendritic cells. J Immunol 1999; 163:3771-7.

21. Durante W, Johnson FK, Johnson RA. Arginase: a critical regulator of nitric oxide synthesis and vascular function. Clin Exp Pharmacol Physiol 2007; 34:906-11.

22. Kobzik L, Bredt DS, Lowenstein CJ et al. Nitric oxide synthase in human and rat lung: immunocytochemical and histochemical localization. Am J Respir Cell Mol Biol 1993; 9:371-7.

23. Hibbs JB, Jr, Taintor RR, Vavrin Z, Rachlin EM. Nitric oxide: a cytotoxic activated macrophage effector molecule. Biochem Biophys Res Commun 1988; 157:87-94.

24. Brightbill HD, Libraty DH, Krutzik SR et al. Host defense mechanisms triggered by microbial lipoproteins through tolllike receptors. Science 1999; 285:732-6.

25. Tarleton RL. Immune system recognition of Trypanosoma cruzi. Curr Opin Immunol 2007; 19:430-4.

26. Marks-Konczalik J, Chu SC, Moss J. Cytokine-mediated transcriptional induction of the human inducible nitric oxide synthase gene requires both activator protein 1 and nuclear factor kappaB-binding sites. J Biol Chem 1998; 273:22201-8.

27. Cifone MG, Cironi L, Meccia MA et al. Role of nitric oxide in cell-mediated tumor cytotoxicity. Adv Neuroimmunol 1995; 5:443-61. 
28. Utsumi T, Mizuta T, Fujii Y et al. Nitric oxide production by bronchoalveolar cells during allograft rejection in the rat. Transplantation 1999; 67:1622-6.

29. Heck DE, Kagan VE, Shvedova AA, Laskin JD. An epigrammatic (abridged) recounting of the myriad tales of astonishing deeds and dire consequences pertaining to nitric oxide and reactive oxygen species in mitochondria with an ancillary missive concerning the origins of apoptosis. Toxicology 2005; 208:259-71.

30. Sun J, Steenbergen C, Murphy E. S-nitrosylation: NO-related redox signaling to protect against oxidative stress. Antioxid Redox Signal 2006; 8:1693-705.

31. Hess DT, Matsumoto A, Nudelman R, Stamler JS. S-nitrosylation: spectrum and specificity. Nat Cell Biol 2001; 3:E46-9.

32. Hess DT, Matsumoto A, Kim SO et al. S-nitrosylation: purview and parameters. Nat Rev Mol Cell Biol 2005; 6:150-66.

33. Melino G, Bernassola F, Knight RA et al. S-nitrosylation regulates apoptosis. Nature 1997; 388:432-3.

34. Thomson L, Gadelha FR, Peluffo G, Vercesi AE, Radi R. Peroxynitrite affects $\mathrm{Ca} 2+$ transport in Trypanosoma cruzi. Mol Biochem Parasitol 1999; 98:81-91.

35. Rubbo H, Denicola A, Radi R. Peroxynitrite inactivates thiol-containing enzymes of Trypanosoma cruzi energetic metabolism and inhibits cell respiration. Arch Biochem Biophys 1994; 308:96-102.

36. Ascenzi P, Salvati L, Bolognesi $\mathrm{M}$ et al. Inhibition of cysteine protease activity by NO-donors. Curr Protein Pept Sci 2001; 2:137-53.

37. McKerrow JH. Development of cysteine protease inhibitors as chemotherapy for parasitic diseases: insights on safety, target validation, and mechanism of action. Int J Parasitol 1999; 29:833-7.

38. Rao MB, Tanksale AM, Ghatge MS, Deshpande VV. Molecular and biotechnological aspects of microbial proteases. Microbiol Mol Biol Rev 1998; 62:597-635.

39. Liaudet L, Soriano FG, Szabo C. Biology of nitric oxide signaling. Crit Care Med 2000; 28:N37-52.

40. Abulencia A, Adelman J, Affolder T et al. Measurement of sigma Lambda b0/sigma B0 x B(Lambda b0-->Lambda c+pi-)/B(B0-$>\mathrm{D}+\mathrm{pi}-)$ in $\mathrm{pp}$ collisions at square root $\mathrm{s}=1.96 \mathrm{TeV}$. Phys Rev Lett 2007; 98:1220-02.

41. Szabo C, Ischiropoulos H, Radi R Peroxynitrite: biochemistry, pathophysiology and development of therapeutics. Nat Rev Drug Discov 2007; 6:662-80.

42. Marnett LJ, Riggins JN, West JD. Endogenous generation of reactive oxidants and electrophiles and their reactions with DNA and protein. J Clin Invest 2003; 111:583-93.

43. Bundy RE, Marczin N, Chester AH, Yacoub M. A redox-based mechanism for nitric oxide-induced inhibition of DNA synthesis in human vascular smooth muscle cells. Br J Pharmacol 2000; 129:1513-21.

44. Kim YM, Son K, Hong SJ et al. Inhibition of protein synthesis by nitric oxide correlates with cytostatic activity: nitric oxide induces phosphorylation of initiation factor eIF-2 alpha. Mol Med 1998; 4:179-90.

45. Roxstrom-Lindquist K, Palm D, Reiner D et al. Giardia immunity-an update. Trends Parasitol 2006; 22:26-31.

46. Flanagan PA. Giardia diagnosis, clinical course and epidemiology. A review. Epidemiol Infect 1992; 109:1-22.

47. Nash TE, Herrington DA, Losonsky GA, Levine MM. Experimental human infections with Giardia lamblia. J Infect Dis 1987; 156:974-84.

48. Li E, Zhou P, Singer SM. Neuronal nitric oxide synthase is necessary for elimination of Giardia lamblia infections in mice. J Immunol 2006; 176:516-21.
49. Andersen YS, Gillin FD, Eckmann L. Adaptive immunity-dependent intestinal hypermotility contributes to host defense against Giardia spp. Infection and Immunity 2006; 74:2473-2476.

50. Faubert G. Immune response to Giardia duodenalis. Clin Microbiol Rev 2000; 13:35-54.

51. Eckmann L. Mucosal defences against Giardia. Parasite Immunol 2003; 25:259-70.

52. Fang FC. Perspectives series: host/pathogen interactions. Mechanisms of nitric oxide-related antimicrobial activity. J Clin Invest 1997; 99:2818-25.

53. Nathan C, Shiloh MU. Reactive oxygen and nitrogen intermediates in the relationship between mammalian hosts and microbial pathogens. Proc Natl Acad Sci U S A 2000; 97:8841-8.

54. De Groote MA, Fang FC. NO inhibitions: antimicrobial properties of nitric oxide. Clin Infect Dis 1995; 21 Suppl 2:S162-5.

55. Murray HW, Nathan CF. Macrophage microbicidal mechanisms in vivo: reactive nitrogen versus oxygen intermediates in the killing of intracellular visceral Leishmania donovani. J Exp Med 1999; 189:741-6.

56. Stenger S, Donhauser N, Thuring H, Rollinghoff M, Bogdan C. Reactivation of latent leishmaniasis by inhibition of inducible nitric oxide synthase. J Exp Med 1996; 183:1501-14.

57. Adams LB, Hibbs JB, Jr, Taintor RR, Krahenbuhl JL. Microbiostatic effect of murine-activated macrophages for Toxoplasma gondii. Role for synthesis of inorganic nitrogen oxides from L-arginine. J Immunol 1990; 144:2725-9.

58. Brunet LR. Nitric oxide in parasitic infections. Int Immunopharmacol 2001; 1:1457-67.

59. James SL. Role of nitric oxide in parasitic infections. Microbiol Rev 1995; 59:533-47.

60. Wynn TA, Oswald IP, Eltoum IA et al. Elevated expression of Th1 cytokines and nitric oxide synthase in the lungs of vaccinated mice after challenge infection with Schistosoma mansoni. J Immunol 1994; 153:5200-9.

61. Nathan CF, Hibbs JB, Jr. Role of nitric oxide synthesis in macrophage antimicrobial activity. Curr Opin Immunol 1991; 3:65-70.

62. Nathan C, Xie QW. Nitric oxide synthases: roles, tolls, and controls. Cell 1994; 78:915-8.

63. Vespa GN, Cunha FQ, Silva JS. Nitric oxide is involved in control of Trypanosoma cruzi-induced parasitemia and directly kills the parasite in vitro. Infect Immun 1994; 62:5177-82.

64. Silva JS, Machado FS, Martins GA. The role of nitric oxide in the pathogenesis of Chagas disease. Front Biosci 2003; 8:s314-25.

65. Chakravortty D, Hensel M. Inducible nitric oxide synthase and control of intracellular bacterial pathogens. Microbes Infect 2003; 5:621-7.

66. Clark IA, Rockett KA. Nitric oxide and parasitic disease. Adv Parasitol 1996; 37:1-56.

67. Chaves Mdel P, Fernandez JA, Ospina I et al. Giardia duodenalis prevalence and associated risk factors in preschool and school-age children of rural Colombia. Biomedica 2007; 27:345-51.

68. Eckmann L, Laurent F, Langford TD et al. Nitric oxide production by human intestinal epithelial cells and competition for arginine as potential determinants of host defense against the lumen-dwelling pathogen Giardia lamblia. J Immunol 2000; 164:1478-87.

69. Islam AT, Kuraoka A, Kawabuchi M. Morphological basis of nitric oxide production and its correlation with the polysialylated precursor cells in the dentate gyrus of the adult guinea pig hippocampus. Anat Sci Int 2003; 78:98-103.

70. Hoffman RA, Langrehr JM, Dull KE, Simmons RL. Nitric oxide production by mouse sponge matrix allograft-infiltrating cells. Comparison with the rat species. Transplantation 1993; 55:591-6.

71. Fernandes PD, Assreuy J. Role of nitric oxide and superoxide in Giardia lamblia killing. Braz J Med Biol Res 1997; 30:93-9. 
72. Morrison HG, McArthur AG, Gillin FD et al. Genomic minimalism in the early diverging intestinal parasite Giardia lamblia. Science 2007; 317:1921-6.

73. Brown DM, Upcroft JA, Upcroft P. Free radical detoxification in Giardia duodenalis. Mol Biochem Parasitol 1995; 72:47-56.

74. Ringqvist E, Palm JE, Skarin $\mathrm{H}$ et al. Release of metabolic enzymes by Giardia in response to interaction with intestinal epithelial cells. Mol Biochem Parasitol 2008; 159:85-91.

75. Oberhuber G, Kastner N \& Stolte M. Giardiasis: a histologic analysis of 567 cases. Scandinavian Journal of Gastroenterology $1997 ; 32: 48$.

76. Singer SM, Nash, TE. T-cell-dependent control of acute Giardia lamblia infections in mice. Infection and Immunity 2000 ; 68:170.

77. Langford TD, Housley MP, Boes et al. Central importance of immunoglobulin A in host defense against Giardia spp. Infection and Immunity 2002; 70:11.

78. Daniels CW, Belosevic M. Serum antibody responses by male and female C57BL / 6 mice infected with Giardia muris. Clinical and Experimental Immunology 1994; 97:424.

79. Char S, Shetty N, Narasimha M. Serum antobidy response in children with Giardia lamblia and infection of an immunodominant 57-kilodalton antigen. Parasite Immunol1991; 13:329-337.
80. Char S, Cevallo AM, Yamson P. Impaired IgA response to Giardia heat-shock antigen in children with persistent diarrhoea and giardiasis. Gut 1993; 34:38-40.

81. Djamiatun K, Faubert GM. Exogenous cytokines released by spleen and Peyer's patch cells removed from mice infected with Giardia muris. Parasite Immunol. 1998; 20:27-36.

82. Mahmoud MS, Salem AA, Rifaat MM. Human giardiasis as an etiology of skin allergy: the role of adhesion molecules and interleukin-6. J Egypt Soc Parasitol. 2004; 34:723-37.

83. Bayraktar MR, Mehmetb N, Durmaza R. Serum cytokine changes in Turkish children infected with Giardia lamblia with and without allergy: Effect of metronidazole treatment. Acta Tropica 2005; 95:116-122.

84. Sonoda E, Matsumoto R, Hitoshi Y et al. Transforming growth factorb induces IgA production and acts additively with interleukin 5 for IgA production. Journal of Experimental Medicine 1989; 170:1415-23.

85. Coffman RL, Lebman DA, Shrader B. Transforming growth factor-b specifically enhances IgA production by lipopolysaccharide-stimulated murine B lymphocytes. Journal of Experimental Medicine 1998; 170:1039-47.

86. Taherkhani H, Hajilooi M, Fallah M et al. Gene polymorphism in transforming growth factor-beta codon 10 is associated with susceptibility to Giardiasis. Int J Immunogenet. 2009; 36:345-9. 